\title{
CUANDO HUMOR Y CULTURA CHOCAN: EL SUBTITULADO EN OCHO APELLIDOS VASCOS ${ }^{1}$
}

\author{
Pilar González Vera \\ pilargv@unizar.es \\ Universidad de Zaragoza
}

\section{Resumen}

La traducción del humor presenta uno de los retos más difíciles y atractivos para el traductor. Esto se debe en gran medida a la diversidad de elementos que pueden llegar a confluir con un único propósito: conseguir arrancar una sonrisa al espectador. En el caso de los productos audiovisuales, a pesar de que la concurrencia de múltiples códigos puede suponer, a priori, una ayuda, no siempre es así al entrar en juego aspectos ideológicos y culturales. El presente trabajo tiene como objetivo el estudio de la traducción del humor en la película Ocho apellidos vascos (Martínez Lázaro 2014), una comedia basada en el choque cultural entre comunidades. A partir del análisis del subtitulado, se procurará contribuir al debate sobre la traducibilidad del humor, prestando especial atención a aquellos casos donde el componente cultural sea determinante o altamente significativo.

\begin{abstract}
"When humour and culture clash: subtitling in Spanish affair"

The translation of humour presents one of the most difficult and attractive challenges for translators. This is, mainly, due to the diversity of elements that can converge with a single purpose: to obtain a smile from the audience. Regarding audiovisual products, despite the concurrence of multiple codes, which may, in the first instance, be of assistance, this is not always the case when ideological and cultural elements come into play. This work aims to study the translation of humour in the film Spanish affair (Martínez Lázaro 2014), a comedy based on the culture clash between communities. From the
\end{abstract}

1. Este artículo ha sido financiado por el Gobierno de Aragón, grupo consolidado Swift H46 y Fondo Europeo de Desarrollo Regional. 
analysis of the subtitling, we intend to contribute to the debate about traductibility of humour, paying special attention to those cases in which the cultural component is determining or, at least, extremely meaningful.

Palabras clave: Humor. Cultura. Traducibilidad. Ocho apellidos vascos. Subtitulado.

Key words: Humour. Culture. Traductibility. Spanish affair. Subtitling.

Manuscript received on June 26, 2016 and accepted for publication on October 9, 2016.

Para enlazar con este artículo / To link to this article:

http://dx.doi.org/10.6035/MonTI.2017.9.9

Para citar este artículo / To cite this article:

GONZÁLEZ VERA, Pilar. (2017) "Cuando humor y cultura chocan: el subtitulado en Ocho apellidos vascos." In: Martínez Sierra, Juan José \& Patrick Zabalbeascoa Terran (eds.) 2017. The Translation of Humour / La traducción del humor. MonTI 9, pp. 249-277. 


\section{Introducción}

El presente estudio trata de valorar la traducibilidad del humor en la versión subtitulada al inglés de una comedia española cuyo humor radica en los conflictos culturales de distintas comunidades. Para ello, se tienen en cuenta las hipótesis de investigadores como Chiaro (2005), que defiende la posibilidad de traducir los textos humorísticos, aunque, eso sí, distinguiéndola de la imposibilidad de la equivalencia; la de Newmark (1988: 107), quien afirma que "all jokes are translatable, but they do not always have the same impact"; y otras menos proclives a la defensa de la traducibilidad en ciertos momentos, como la de Santoyo (1994: 145), quien sostiene que, en la medida en que el humor de una situación o comedia derive de la utilización de elementos específicamente culturales, en esa misma medida su trasvase a otros idiomas, o lo que es lo mismo, su traducción, se verá seriamente dificultada, si no del todo limitada.

Como punto de partida se incluye una breve revisión de los enfoques desde los que se ha tratado el humor, prestando una especial atención a las investigaciones vinculadas con la traducción audiovisual. En segundo lugar, se presenta la película que sirve de corpus para el estudio, Ocho Apellidos Vascos, y se indica el criterio seguido para la clasificación de los ejemplos analizados. Finalmente, se incluyen las conclusiones extraídas, así como una propuesta de posibles vías de investigación futura.

\section{Marco teórico del humor}

El humor ha sido sujeto de estudio a lo largo del tiempo por la gran complejidad que envuelve. A esto hay que añadir que los enfoques desde los que se ha acometido su estudio han estado continuamente evolucionando y perfilándose. Muestra de este recorrido se encuentra en la revisión de la literatura publicada en torno al humor realizada por Santana López (2005) y que recoge las distintas perspectivas desde las que se ha analizado el humor. La autora agrupa las investigaciones según se hayan realizado desde las teorías lingüísticas, las literarias, las culturales o las llevadas a cabo dentro del marco de la comunicación audiovisual. 
En la disciplina lingüística hay que destacar las investigaciones realizadas por Attardo \& Raskin (1991), que desembocan en la Teoría general del humor verbal y que gira en torno al aspecto lingüístico de los chistes. En esta misma línea destacan los estudios presentados por Chiaro (2000, 2005, 2010), en los que profundiza en el humor verbal dentro del campo de la traducción audiovisual y la recepción del humor. Por su parte, Delabastita propone un estudio del humor como elemento estilístico y parte de las obras literarias, centrándose en el juego de palabras, al que define como

the general name for the various textual phenomena in which structural features of the language(s) used are exploited in order to bring about a communicatively significant confrontation of two (or more) linguistic structures with more or less similar forms and more or less different meanings (1996: 128).

El mismo autor clasifica los juegos de palabras en cuatro tipos: homonimia (dos palabras que suenan y se escriben igual, pero tienen distinto significado), homofonía (dos palabras con sonido idéntico, pero con distinta forma escrita), homografía (dos palabras que se escriben igual, pero suenan distintas) y paronimia (dos palabras muy parecidas, pero entre las que hay diferencias a la hora de pronunciarlas y escribirlas). A estos se añade el portmanteau (compuesto), "a label for the coinage that packs two meanings into one word" (Nash 1985: 143).

En lo que respecta a la faceta cultural del humor, Vandaele (2002) elabora una minuciosa revisión bibliográfica del estudio del humor partiendo de una perspectiva lingüística e incorporando la sociolingüística y un enfoque metalingüístico que le lleva a establecer una relación lengua-cultura en el humor. Este nexo también se percibe en los estudios del humor dentro de la traducción audiovisual. Muestra de ello es la clasificación de los chistes planteada por Zabalbeascoa (1996) y que sirve de sustento para las propuestas por Fuentes (2000) y Martínez Sierra (2004) (Tabla 1). 


\begin{tabular}{|c|c|c|c|c|}
\hline & \multicolumn{3}{|c|}{ Chistes simples } & Chistes \\
\hline \multirow{7}{*}{ Cambios } & Zabalbeascoa & Fuentes & Martínez Sierra & \multirow{7}{*}{$\begin{array}{l}\text { Combinación } \\
\text { de dos o } \\
\text { más tipos de } \\
\text { elementos }\end{array}$} \\
\hline & Chistes binacionales & & $\begin{array}{l}\text { Elementos } \\
\text { no-marcados }\end{array}$ & \\
\hline & $\begin{array}{c}\text { Chistes sobre la cultura } \\
\text { y las instituciones } \\
\text { nacionales }\end{array}$ & & $\begin{array}{l}\text { Elementos sobre } \\
\text { la comunidad e } \\
\text { instituciones }\end{array}$ & \\
\hline & $\begin{array}{l}\text { Chistes de sentido del } \\
\text { humor nacional }\end{array}$ & & $\begin{array}{c}\text { Elementos de sentido } \\
\text { del humor de la } \\
\text { comunidad }\end{array}$ & \\
\hline & $\begin{array}{c}\text { Chistes dependientes de } \\
\text { la lengua }\end{array}$ & & $\begin{array}{l}\text { Elementos } \\
\text { lingüísticos }\end{array}$ & \\
\hline & Chistes visuales & & Elementos visuales & \\
\hline & & $\begin{array}{l}\text { Chistes } \\
\text { sonoros }\end{array}$ & $\begin{array}{c}\text { Elementos } \\
\text { paralingüísticos }\end{array}$ & \\
\hline \multicolumn{3}{|l|}{ Adiciones } & Elementos gráficos & \\
\hline
\end{tabular}

Tabla 1 - Tipología de elementos humorísticos de los chistes y comparativa con las propuestas de otros autores, según Martínez Sierra (2004: 222).

Si atendemos a la clasificación de Martínez Sierra, el autor, a diferencia de Zabalbeascoa, no se refiere a tipos de chistes sino a chistes que contienen distintos elementos. Así, en el caso de los chistes con elementos no-marcados incluye aquellos que son resultado de una situación y en los que ni el lenguaje ni las diferencias culturales son determinantes para conseguir el efecto cómico, por lo que su traducción no comporta grandes dificultades. El segundo alude a los referentes culturales específicos de una comunidad, como celebridades, programas televisivos, etc., o intertextuales y que en ocasiones se adaptan a los de la meta con el fin de ser humorísticos (familiarización). El tercero, por su parte, tiene un matiz más global, al no ceñirse a referentes concretos sino a temáticas populares dentro de una comunidad como valores, creencias o estereotipos. Los elementos lingüísticos están relacionados con el uso del lenguaje, por ejemplo, los juegos de palabras, mientras que los visuales difieren de los gráficos en que en los primeros el humor proviene de lo visto en la pantalla y en los segundos se limita a mensajes escritos en pantalla, bien sean títulos, didascalias, textos o subtítulos. Por último, los paralingüísticos recogen elementos como los acentos, tonos de voz o imitaciones de la forma de hablar de algún famoso (Martínez Sierra 2004: 215). 
Si bien es cierto que la posibilidad de traducir o no el humor ha sido cuestionada por la dificultad que entraña, esta es aún mayor si se trata del subtitulado, al encontrarnos con los límites que impone esta modalidad caracterizada por ser (Gottlieb 1992: 162):

- Written (Subtitles are not received via hearing as in the case of dubbing).

- Additive (The translated text provides a supplement to the original).

- Immediate ("As opposed to non-synchronous translations, where the receptor - reading a book, for instance - controls both time and duration for reception". With subtitles, however, the audience cannot go back or slow down the material).

- Synchronous (The original and the translated text are received at the same time, contrary to simultaneous interpreting).

- Polymedial (This means the coexistence of two or more channels delivering the meaning of the source text).

Así, cuando pasamos al subtitulado, la labor se complica, puesto que la traducción del humor en subtítulos "is not as straightforward as the translation of written, totally verbal word play, or even of the interpretation of an orally produced pun" (Chiaro 2000: 32). A la materialización del humor a través de las palabras y de las imágenes en los textos audiovisuales se añade las implicaciones del paso del medio oral al escrito en el subtitulado, que llevan a una reformulación del texto y a un proceso de edición donde suele predominar la condensación. Si además tenemos en cuenta el componente cultural nos encontramos con que en el subtitulado partimos de tres dificultades: 1) las restricciones espacio-temporales, 2) el paso de registro hablado a escrito, y 3 ) el paso de una cultura a otra (Gottlieb 1994: 104-106), que tienen que valorarse para conseguir un traspaso correcto.

\section{Análisis del humor en Ocho Apellidos Vascos}

La película española elegida para estudiar la traducción del humor al subtitulado en inglés se trata de Ocho Apellidos Vascos (Spanish Affair, Martínez-Lázaro 2014). Esta comedia romántica narra las aventuras de Rafa, un auténtico sevillano, que impulsivamente viaja al norte de España para intentar conseguir el amor de Amaia, una vasca con fuerte carácter a la que ha dejado su novio en vísperas de la boda, y a la que ha conocido una noche en Sevilla. Una vez en el País Vasco, Rafa se tiene que hacer pasar por vasco y novio de Amaia a la vez que enfrentarse a los prejuicios sobre la gente y el estilo de vida en esta comunidad. Este choque cultural de norte (País Vasco) y sur (Andalucía) en 
el que se concatenan estereotipos y clichés da lugar a numerosas situaciones cómicas que, a su vez, se convierten en hilo discursivo de la trama.

Tras visionar la película y localizar las escenas en las que se apreciaba algún caso de humor, se procedió a su clasificación a partir de los elementos humorísticos descritos por Martínez Sierra (2004) que concurren en las escenas. Al poder confluir varios de estos elementos en la misma escena, se ha optado por clasificar los ejemplos de acuerdo con el elemento humorístico dominante. Con el fin de simplificar la nomenclatura de los elementos humorísticos que se analizan en los ejemplos, se seguirá la siguiente codificación (Tabla 2):

\begin{tabular}{|c|c|}
\hline NM & Elementos no-marcados \\
\hline CI & Elementos sobre la comunidad e instituciones \\
\hline SHC & Elementos de sentido del humor de la comunidad \\
\hline L & Elementos lingüísticos \\
\hline V & Elementos visuales \\
\hline P & Elementos paralingüísticos \\
\hline G & Elementos gráficos \\
\hline
\end{tabular}

Tabla 2 - Abreviaturas de los tipos de elementos humorísticos (Martínez Sierra 2004).

\subsection{Elementos no marcados}

La película cuenta con situaciones humorísticas provocadas por elementos no marcados y en las que el traductor no tiene que buscar soluciones complicadas para conseguir el mismo efecto humorístico del original, tal y como sucede en:

(1) Primer ejemplo

Versión original (VO)

Koldo: Bueno, fenómeno. ¿Dónde vives tú?

Rafa: Pues entre las afueras y el centro, en el medio.
Versión original subtitulada (VOS)

Koldo: All right, where do you live?

Rafa: Between the outskirts and the centre, in the middle.

\subsection{Elementos paralingüísticos}

Sin embargo, la versión original se caracteriza por recurrir a elementos humorísticos paralingüísticos que no son siempre fáciles de trasladar. Entre otros elementos paralingüísticos, en la película destacan la imitación del acento vasco que realiza Rafa y el uso forzado que hace este personaje de palabras sueltas que intentan asemejarse a vocablos en euskera y que dan lugar a discursos 
inconexos y absurdos, como por ejemplo cuando Koldo se ofrece a llevarle a casa y este le responde:

(2) Segundo ejemplo

\begin{tabular}{|c|c|}
\hline $\begin{array}{l}\text { VO. } \\
\text { Rafa: Eskerrik asko, Koldo. Osendo, } \\
\text { perfectoak. Agur. }\end{array}$ & $\begin{array}{l}\text { VOS. } \\
\text { Rafa: Eskerrik asko, Koldo. Osendo, } \\
\text { perfectoak. Agur. }\end{array}$ \\
\hline
\end{tabular}

Rafa combina palabras en euskera como eskerrik asko (muchas gracias) y agur (adiós) con otras que imitan al euskera añadiendo sufijos típicos de la lengua como -oak en "perfectoak" (perfektua, perfecto), o por semejanza, como "osendo" (oso ondo, muy bien). El mismo Rafa emplea el elemento paralingüístico, o la variedad dialectal según Del Corral (1988: 26), de forma intencionada para contar un chiste sobre vascos:

\section{(3) Tercer ejemplo}

\begin{tabular}{|l|l|}
\hline VO. & VOS. \\
Rafa: Esto son dos vascos que se & Rafa: These two Basques meet and one \\
encuentran y le dice el uno al otro: "Oye & says: "Hey, Patxi, I hear your daughter's in \\
Patxi, qué me enterau que tu hija está en la & bed with gonorrhea." The other says: "I \\
cama con gonorrea". Y el otro dice: "A mí & don't care! as long as he's Basque..." \\
qué hostias, mientras sea vasco". & \\
\hline
\end{tabular}

En el chiste imita el acento vasco y establece un juego entre el término "gonorrea" y su parecido con lo que pudiera ser el nombre de alguien en euskera, por la dificultad de su pronunciación. Sin embargo, la traducción literal en la versión subtitulada hace que se pierda el efecto humorístico. Una situación similar ocurre cuando Koldo propone una salida a por bonito y al decir que es pescador, Merche confunde el término arrantzale por lo que podría ser el nombre de Koldo, contestando que ella se llama Anne, nombre que ella se pone para pasar por vasca, y provocando una situación absurda. En este caso la traducción literal permite mantener el humor, ya que la audiencia conoce el verdadero nombre de Koldo, por lo que imagina que arrantzale no se corresponde con el nombre y que puede tratarse de una profesión.

\section{(4) Cuarto ejemplo}

\begin{tabular}{l|l|}
\hline VO. & VOS. \\
Koldo: Oye, mañana si queréis podemos & Koldo: Tomorrow we could go fishing for \\
salir a pescar un bonito [...] soy arrantzale. & bonito [...] I'm arrantzale. \\
Merche: Y yo Anne, encantada. & Merche: And I'm Anne. A pleasure. \\
\hline
\end{tabular}


Esta misma línea de humor basado en la confusión entre un término en euskera y un nombre propio tiene de nuevo lugar cuando Rafa, recién llegado de Sevilla, se presenta por sorpresa en casa de Amaia quien, desconcertada, le amenaza con llamar a la ertzaintza. El término que designa a la policía del País Vasco es confundido por Rafa con el nombre de alguna amiga de Amaia, al asemejarse fonéticamente con el nombre de Arantxa:

(5) Quinto ejemplo

\begin{tabular}{|l|l|}
\hline VO. & VOS. \\
Amaia: ¿Qué quieres que llame a la & Amaia: You want me to call the \\
Ertzaintza, o qué? & Ertzaintza? \\
Rafa: Hombre, yo había pensao estar un & Rafa: I thought we'd be on our own for a \\
ratito los dos a solas al principio, pero si & while, but call your friend if you want. \\
llamas a una amiga tampoco pasa nada. &
\end{tabular}

El uso del euskera como elemento lingüístico desencadenante de situaciones humorísticas es frecuente a lo largo de la película, como hemos podido observar. En los ejemplos anteriores el humor surge a raíz de los malos entendidos y situaciones absurdas que son fruto de la falta de comprensión del euskera, pero también el uso del euskera combinado con el castellano, dando lugar a nuevas palabras (portmanteau), es empleado en situaciones humorísticas, tal y como sucede en los siguientes ejemplos:

(6) Sexto ejemplo

\begin{tabular}{|l|l|}
\hline VO. & VOS. \\
$\begin{array}{l}\text { Amaia: Y deja de hacer la pelota con tanto } \\
\text { abrazo y tanta hostia. Para qué das un } \\
\text { abrazo, que no estás en Sevilla. }\end{array}$ & Amaia: And stop all the hugging. \\
$\begin{array}{l}\text { Rafa: Cúsame, iparezco "aberchándal"? } \\
\text { Amaia: Abertzale. }\end{array}$ & $\begin{array}{l}\text { Rafa: Do I look "uppersally"? } \\
\text { Rafa: Sí, ¿no? }\end{array}$ \\
\hline
\end{tabular}

(7) Séptimo ejemplo

\begin{tabular}{|l|l|}
\hline $\begin{array}{l}\text { VO. } \\
\text { Rafa: Pero que yo soy sevillano. Como } \\
\text { queréis que os lo diga, que yo no } \\
\text { pertenezco a la escalera borroca esa. }\end{array}$ & $\begin{array}{l}\text { VOS. } \\
\text { Rafa: I'm Sevillian, don't you understand? } \\
\text { I don't belong to that "galleyborroca." }\end{array}$ \\
\hline
\end{tabular}

En los dos casos Rafa modifica el euskera, y produce una nueva palabra con alusiones a la temática popular y clichés sobre la comunidad (SHC) del País Vasco con efecto humorístico. En el primer caso, "aberchándal", toma el principio de 
la palabra abertzale (patriota) y por semejanza fonética sustituye "-tzale" por "chandal". Así consigue un guiño a los clichés sobre la comunidad asociados a la preferencia de los vascos por vestir de manera informal, por ejemplo, chándales. En la versión subtitulada al inglés se ha optado por mantener el humor basado en la conjunción de dos palabras, super y chavvy, que aluden a la falta de gusto en el vestir. Sin embargo, el hecho de que se trate de un estereotipo sobre la comunidad puede pasar desapercibido para la audiencia meta.

En el segundo caso, "calera borroca" proviene de la expresión en euskera kale borroka (lucha en la calle), con un alto significado para la comunidad (SHC), ya que se refiere al grupo de jóvenes que defendían la independencia del País Vasco a través de la lucha en la calle. El efecto humorístico proviene de la semejanza fonética del original con el sinsentido creado por Rafa, "escalera barroca". Como sucediera en el ejemplo anterior, para el subtitulado se ha optado por una palabra inventada que podría recordar las palabras galley y barroque, pero, nuevamente, la alusión a aspectos culturales sobre la comunidad podrán pasar inadvertidos para el espectador meta.

\subsection{Elementos de sentido del humor de la comunidad}

El elemento paralingüístico está presente en numerosas ocasiones humorísticas protagonizadas por Rafa y, en ocasiones, se combina con elementos de sentido del humor de la comunidad (SHC), como en la escena en la que Rafa, tras haber comido y bebido en exceso, tiene que vomitar en unos arbustos y, al interesarse Koldo por él, Rafa contesta:

(8) Octavo ejemplo

\begin{tabular}{l|l|}
\hline VO. & VOS. \\
Rafa: Estaba mirando a ver si había \\
$\begin{array}{l}\text { alguna seta interesante. Pero nada, todo } \\
\text { champiñones y boletua. Koldo, eskerrik } \\
\text { asko por la cena. }\end{array}$ & $\begin{array}{l}\text { any interesting mushrooms. But they're all } \\
\text { button mushrooms and "boletua." Koldo, } \\
\text { eskerrik asko for dinner. }\end{array}$ \\
\hline
\end{tabular}

Así, la situación humorística resulta más compleja, ya que el uso de la palabra en euskera (eskerrik asko) se combina con la creación de "boletua", palabra basada en el término boletus, al que se le añade una terminación típica, -ua, y con una afición como es la de buscar setas que se asocia a los vascos y que ha servido como recurso en diversos chistes sobre la comunidad.

El uso de elementos de sentido del humor de la comunidad (SHC) y que aluden a los estereotipos sobre las comunidades es el motor principal del humor en la película. Fundamentalmente, los valores y creencias que giran en 
torno a la comunidad vasca, entre los que destacan: la pasión por la gastronomía, la tendencia a exagerar, el tema del terrorismo, el fuerte carácter y la descripción de las mujeres dentro de la comunidad.

La gastronomía es uno de los emblemas del territorio vasco, cuna de grandes chefs. Los vascos son conocidos por su entusiasmo por el buen comer y el tamaño de las cantidades a las que están acostumbrados. Muestra de ello es la escena en la que el camarero recita los distintos platos que forman parte del menú y Rafa piensa que tiene que elegir al resultar en su conjunto excesivo. En la versión subtitulada al inglés, el efecto humorístico basado en la exageración se consigue gracias a la traducción de cada uno de los numerosos platos que componen el menú. A pesar de que la audiencia meta puede apreciar el elemento NM que resulta de la suma de 1) la desproporción de comida y 2) la postura dramatizada de Rafa en "and all the rest too. I hope it's enough", el elemento SHC puede perderse si la audiencia meta desconoce las creencias sobre la comunidad vasca en torno a la gastronomía y su tendencia a la exageración.

(9) Noveno ejemplo

\begin{tabular}{|c|c|}
\hline $\begin{array}{l}\text { VO. } \\
\text { Camarero: Pues hoy tenemos alubias, } \\
\text { ensalada mixta, pimientos rellenos de } \\
\text { txangurro, croquetas de bacalao, revueltito } \\
\text { de hongos, chipirones en su tinta, cogote } \\
\text { de merluza y chuletón de buey. } \\
\text { Rafa: Yo los chipirones. } \\
\text { Camarero: No es a elegir. Eso es lo que } \\
\text { viene con el menú. Aquí se come lo que } \\
\text { hay. } \\
\text { Amaia: No, no, que los chipirones es lo que } \\
\text { más ganas tiene Antxon. [...] } \\
\text { Rafa: Pero de lo demás también. A ver si } \\
\text { me voy a quedar con hambre. }\end{array}$ & $\begin{array}{l}\text { VOS. } \\
\text { Camarero: Tonight we have beans, mixed } \\
\text { salad, peppers stuffed with txangurro, } \\
\text { cod croquettes, scrambled egg with } \\
\text { mushrooms, squid in its own ink, nape } \\
\text { of hake and T-bone steak. } \\
\text { Rafa: I'll have squid. } \\
\text { Camarero: You don't choose. That's the } \\
\text { set meal. Here, you eat what there is. } \\
\text { Amaia: No, squid is just what Antxon } \\
\text { likes most. [...] } \\
\text { Rafa: And all the rest too. I hope it's } \\
\text { enough. }\end{array}$ \\
\hline
\end{tabular}

Otro caso relacionado con los valores sobre la gastronomía es el momento en el que Koldo cuestiona hasta qué punto puede considerarse a Rafa completamente vasco por apellidarse Clemente. El tener un apellido no vasco implica un signo de no pertenencia a la comunidad, lo que subraya Koldo en:

(10) Décimo ejemplo

\begin{tabular}{|l|l|}
\hline VO. & VOS. \\
Amaia: Así que hala, ¿vamos a cenar? & Amaia: So, shall we eat? \\
Koldo: Bueno, bueno. Pero este igual, como & Koldo: All right. But as he's a Clemente, \\
es Clemente, se pide paella o algo, eh. & he might order paella. \\
\hline
\end{tabular}


El sentido del humor se consigue a través del silogismo entre Clemente-paellaEspaña vs. apellido vasco-cocina vasca-País Vasco. En el caso de la traducción, la audiencia se puede encontrar con una pérdida del humor si no establece el simbolismo de la paella como plato nacional y emblema nacional frente a la cocina vasca, muy distinta y con gran reputación que permite a la comunidad utilizarlo como rasgo distintivo frente al resto de España.

Otro de los rasgos que caracteriza a los vascos según los estereotipos existentes es la tendencia a exagerar, que va desde las abundantes raciones en la mesa a la forma de hablar y expresarse, como en el chiste que cuenta Rafa y en el que recurre a este cliché:

\section{(11) Undécimo ejemplo}

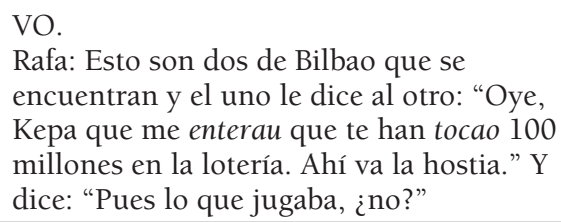

VOS.

Rafa: These two from Bilbao meet, and one says: "Kepa, I hear you won 100 million on the lottery." The other says: "Just what I bet."

Aunque, en este caso, la audiencia meta puede no captar el cliché, el chiste basado en la desproporción del protagonista de este no pasará desapercibido y logrará la misma finalidad que en el texto original: conseguir la carcajada de la audiencia.

Entre los temas relacionados con la comunidad se encuentra el terrorismo, que sirve de recurso humorístico como SHC o en combinación con otros elementos humorísticos, como veremos más adelante (cf. elementos lingüísticos). Ejemplo de elemento humorístico SHC es la escena en la que Amaia asalta el autobús en el que va Rafa para impedirle que regrese a Sevilla, y Rafa le increpa:

\section{(12) Duodécimo ejemplo}

\begin{tabular}{|l|l|}
\hline VO. & VOS. \\
Rafa: ¿Y qué vas a hacer? ¿Me vas a & Rafa: Are you going to kidnap me? \\
secuestrar? A ver, que he dicho "secuestrar" & Look, I said "kidnap" as a manner of \\
en plan manera de hablar. No en plan sulo, & speech. It's nothing political. I know you \\
que yo sé que si vosotros os ponéis... & can be... \\
\hline
\end{tabular}

Ante el comentario de Rafa referido al secuestro, el resto del autobús reacciona, unos desafiantes, otros atemorizados. La alusión en la versión original a esta práctica habitual del grupo terrorista ETA se hace explícita en la versión subtitulada, en la que la expresión "it's nothing political" recalca la dimensión política que esta encierra. 
Por último, entre las situaciones humorísticas (SHC) se encuentran las relacionadas con los estereotipos forjados en torno al carácter y la apariencia física de los vascos y los andaluces. Es aquí donde el personaje de Amaia sirve de detonante para personalizar y, a la vez, cuestionar los estereotipos sobre las mujeres vascas, provocando situaciones como las que a continuación se presentan.

El primer cliché que se encuentra es el de la mujer vasca como mujer ruda, que no sucumbe fácilmente a los hombres y que resulta difícil de conquistar, como en:

\section{(13) Decimotercer ejemplo}

\begin{tabular}{|l|l|}
\hline $\begin{array}{l}\text { VO. } \\
\begin{array}{l}\text { Joaquín: Dormir con una vasca es como } \\
\text { tirarte tres veces a una de Málaga. }\end{array}\end{array}$ & $\begin{array}{l}\text { VOS. } \\
\text { Joaquín: Sleeping with a Basque is like } \\
\text { screwing a girl from Málaga three times. }\end{array}$ \\
\hline
\end{tabular}

\section{También en:}

\section{(14) Decimocuarto ejemplo}

\begin{tabular}{|l|l|}
\hline VO. & VOS. \\
Rafa: Pues esto habrá que prepararlo bien & Rafa: We'll have to prepare this really \\
preparau. & well. \\
Amaia: Por ejemplo, ¿cómo nos conocimos? & Amaia: Like, how did we meet? \\
Rafa: Pues yo qué sé, vamos a tirar de lo & Rafa: Let's say the typical thing. We got \\
típico, en una discoteca y nos liamos. & off at a disco. \\
Amaia: Bueno eso será lo más típico de Ibiza, & Amaia: That might be typical in Ibiza. \\
pero esto es Euskadi. & We're in Euskadi. \\
Rafa: Bueno, pues en un frontón o en un & Rafa: Well, at a pelota game or in a \\
caserío de estos de los vuestros. & farmhouse. \\
Amaia: No, me refiero que aquí el primer día & Amaia: No, I mean couples here don't \\
las parejas no se suelen liar. & usually get off on the first day. \\
Rafa: Pero si tú y yo nos liamos la primera & Rafa: We did on the first night, my \\
noche, imi arma! & love! \\
[...] & [...] \\
Rafa: Que icómo os conocisteis, hostia? & Rafa: How did we meet, shit? \\
Amaia: Nos presentaron unas amigas de su & Amaia: Some friends introduced us. \\
grupo. & \\
Rafa: Amaia, eso es muy soso. Eso no tiene & Rafa: That's really dull. It's got no \\
ni chicha, ni ná. Eso no se lo va a creer. & kick. He won't believe it. OK, we were \\
Bueno ya está, nos presentaron unas amigas & introduced and we got off. \\
tuyas y nos liamos. & \\
Amaia: No, nos presentaron y estuvimos tres & Amaia: No, we were introduced and \\
semanas quedando. & dated for three weeks. \\
Rafa: ¿Tres semanas hasta que os liasteis? & Rafa: Three weeks before you got off? \\
Antxon este era un campeón, eh. & That Antxon was a champ. \\
Amaia: Tres semanas hasta que me pidió el & Amaia: Three weeks until he asked for \\
teléfono. & my number. \\
\hline
\end{tabular}


En los dos casos, el efecto humorístico resulta fácil de transmitir. La audiencia puede ver que se está estableciendo una comparación entre dos tipos de chicas, las del norte y las del sur, y que las costumbres en el tema del flirteo difieren según la zona geográfica. Sin embargo, hay que señalar que las referencias culturales a los caseríos y los frontones del original se ven diluidas en el subtitulado al eliminarse la expresión "de los vuestros", que acentúa las diferencias entre las dos comunidades, si bien esta omisión podría justificarse por las restricciones espacio-temporales propias de esta modalidad.

En lo que respecta a los estereotipos sobre la apariencia física, estos son cuestionados por la belleza de Amaia, dando lugar a situaciones humorísticas. Cuando el compañero de Rafa señala que en el bolso de la chica no haya ningún producto cosmético, el otro camarero apunta que esto se debe a que es porque la chica es vasca, basándose en la idea de que las mujeres vascas no tienen interés por la estética al estar más preocupadas por realizar duros trabajos físicos dentro de su papel matriarcal. A pesar de que Rafa desafía el cliché argumentando que podría ser Miss Euskadi, Joaquín concluye la discusión aseverando que los certámenes de belleza no existen en la comunidad vasca, lo que puede suscitar el humor en el espectador que comprende que se trata de una exageración por parte de Joaquín y que tal afirmación es falsa, como se demuestra por el contexto y la entonación de los personajes:

(15) Decimoquinto ejemplo

\begin{tabular}{|l|l|}
\hline VO. & VOS. \\
Joaquín: Cuidado, Currito, no vaya a ver & Joaquín: Careful, there might be a bomb \\
un artefacto explosivo, hijo. & in there. \\
Currito: ¿Tú estás seguro que este bolso & Currito: Are you sure this is a woman's \\
es el de una mujer? Porque aquí no hay ni & purse? There's no lipstick or mascara or \\
pintalabios, ni rímel, ni nada. & anything. \\
Joaquín: Si las vascas no se maquillan ni & Joaquín: Basque women don't wear \\
ná. & make-up. \\
Rafa: Joaquín, que tú viste a la muchacha, & Rafa: Joaquín, you saw her, she could be \\
que podía ser Miss Euskadi. & Miss Euskadi. \\
Joaquín: Miss Euskadi, eso allí no hay. No & Joaquín: Miss Euskadi? They don't have \\
hay. & that. \\
\hline
\end{tabular}

La apariencia física abarca los distintos estilos a la hora de vestir. Así, el humor surge en las comparaciones que hace Rafa para referirse a Amaia, desde su flequillo a su ropa: 
(16) Decimosexto ejemplo

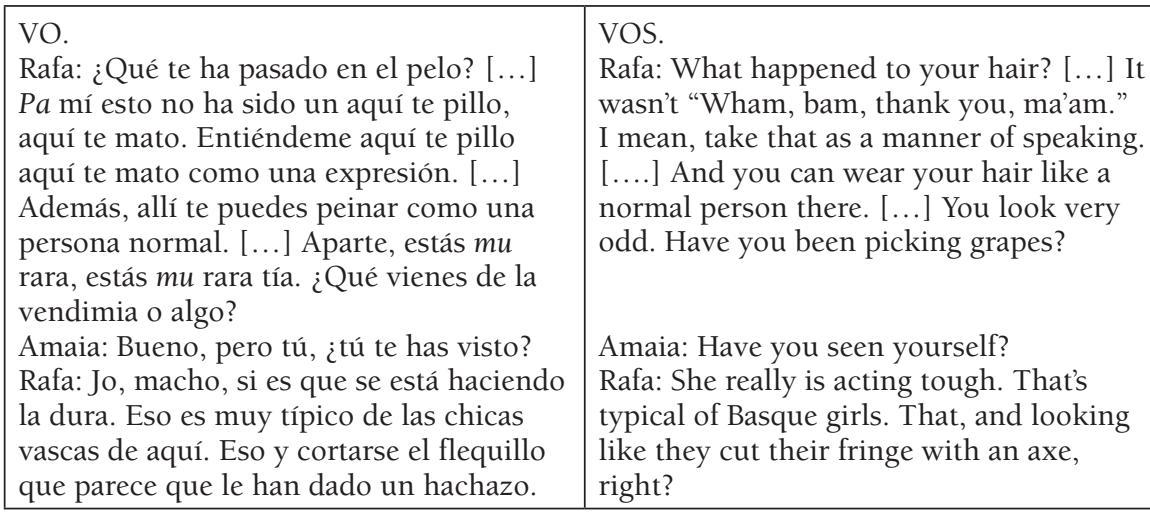

En la escena concurren varios elementos humorísticos, desde los propios de la comunidad (SHC) a visuales (V). El primero referido a la comunidad se trata del comentario de Rafa sobre el encuentro que tuvieron en Sevilla. Al decir que no fue "un aquí te pillo, aquí te mato", y rápidamente añadir que se trata de una expresión, se percibe una alusión al tema del terrorismo que, en cierto modo, se mantiene en la versión subtitulada gracias a "wham, bam" y al contexto que rodea a la acción y permite al espectador comprender a qué se refiere. El siguiente elemento es la combinación del visual, la forma de vestir y peinado de Amaia y las comparaciones que establece Rafa. Tal y como señalan Zabalbeascoa (1997: 336), Fuentes (2001: 43-56) o Martínez Sierra (2009: $141)$, los elementos visuales son una de las restricciones con las que tiene que lidiar el traductor; sin embargo, hay que señalar que tal y como sucede en este ejemplo, la imagen puede contribuir a que la audiencia meta capte la nota humorística. De igual modo, se puede percibir la alusión a los clichés sobre la comunidad gracias a "that's typical of Basque girls".

Los comentarios sobre el flequillo y el estilo informal de Amaia se repiten en la siguiente escena, donde el humor es el protagonista una vez más: 
(17) Decimoséptimo ejemplo

\begin{tabular}{|c|c|}
\hline VO. & VOS. \\
\hline $\begin{array}{l}\text { Rafa: Escúsame, eso será para jugar al frontón } \\
\text { estará muy bien, pero para salir a la calle yo } \\
\text { no lo veo. }\end{array}$ & $\begin{array}{l}\text { Rafa: That might do for playing pelota } \\
\text { but not for the street. }\end{array}$ \\
\hline Amaia: Que esta ropa está bien. & Amaia: These clothes are fine. \\
\hline $\begin{array}{l}\text { Rafa: Esta bien si vengo de recoger aceitunas } \\
\text { en Puente Genil. Pero yo por la noche con } \\
\text { un chándal yo no alterno. }\end{array}$ & $\begin{array}{l}\text { Rafa: They're fine for picking olives but } \\
\text { I don't go out at night in a track suit. }\end{array}$ \\
\hline $\begin{array}{l}\text { Amaia: Y el colgante que llevas, fuera } \\
\text { también. }\end{array}$ & Amaia: And get rid of that necklace. \\
\hline $\begin{array}{l}\text { Rafa: Ah, no. Escúsame, que esto es la Virgen } \\
\text { de la Macarena, eh. Que esto es lo más } \\
\text { grande que hay. }\end{array}$ & $\begin{array}{l}\text { Rafa: No! This is the Virgin of the } \\
\text { Macarena. It's the greatest. }\end{array}$ \\
\hline $\begin{array}{l}\text { Amaia: [...] El móvil, no te vaya a llamar un } \\
\text { amigo tuyo desde la Giralda y la liemos. } \\
\text { Rafa: No solo me quitas mis raíces, sino que } \\
\text { encima me dejas incomunicado. Eso es muy } \\
\text { típico de los radicales vascos. }\end{array}$ & $\begin{array}{l}\text { Amaia: [...] Your phone. We don't want } \\
\text { a friend calling you from the Giralda. } \\
\text { Rafa: You take away my roots, and leave } \\
\text { me incommunicado as well. Typical of } \\
\text { Basque radicals. }\end{array}$ \\
\hline Amaia: Con el pelo hay que hacer algo, eh. & Amaia: And a change of hairstyle. \\
\hline $\begin{array}{l}\text { Rafa: Pos sí, ahí llevas razón. Porque tienes el } \\
\text { flequillo que parece que te ha pegao un bocao } \\
\text { un burro. }\end{array}$ & $\begin{array}{l}\text { Rafa: You're right there, you look like a } \\
\text { donkey chewed your hair. }\end{array}$ \\
\hline Amaia: Hablo de tu gomina. & Amaia: I mean your hair gel. \\
\hline $\begin{array}{l}\text { Rafa: Ah, no, que estás hablando de la } \\
\text { gomina. No, no, tú a mí me trastocas la } \\
\text { religión si quieres, pero la gomina no me la } \\
\text { tocas. Que tú no me tocas el pelo. }\end{array}$ & $\begin{array}{l}\text { Rafa: No way. My hair gel? No, you can } \\
\text { play around with my religion but you're } \\
\text { not touching my hair gel! }\end{array}$ \\
\hline
\end{tabular}

En su conjunto resulta una situación humorística no marcada si se considera la trasformación que lleva a cabo Amaia sobre Rafa. No obstante, la escena está salpicada de referentes culturales y elementos sobre las comunidades. En cuanto a los referentes culturales, la versión original cuenta con "Puente Genil", "la Giralda" y "la Virgen de la Macarena", que se ven reducidos a dos en la versión subtitulada, donde se omite la localidad cordobesa de "Puente Genil". Esta omisión permite al traductor contar con un mayor número de caracteres y no repercute en la versión meta al mantenerse el efecto cómico por la comparación de la forma de arreglarse para salir de Amaia con la vestimenta más propia de los olivareros al trabajar en el campo. Los otros dos referentes culturales se han mantenido intactos en la versión meta; su fama y su fuerte vínculo con la cultura andaluza no pasan desapercibidos, incluyendo entre la audiencia meta, pero no resultan oscuros en la comprensión del texto. Estos referentes van acompañados de referencias a las comunidades andaluza y vasca, y la comparación de estas lleva al humor basado en estereotipos. Muestra de ello es el comentario sobre los peinados que, además de rasgo diferenciador, 
juega un papel humorístico. Por una parte, el símil del corte del flequillo de Amaia, propio del País Vasco, con el de uno mordido por un burro consigue un efecto humorístico que funciona de igual modo en las dos versiones, en cierta manera, gracias a la imagen de la joven. Algo más complejo es la relación de Rafa con la gomina, ya que la imagen no contribuye a crear el efecto humorístico y su uso es más extendido que el corte de pelo de Amaia. A pesar de que en ambos casos los estilismos tienen el valor añadido de ser elementos representativos de la comunidad, el humor aquí proviene de la importancia que le concede Rafa al anteponer la gomina a la religión, aspecto vital para un andaluz según los clichés que se les atribuyen. A estos elementos sobre las comunidades hay que añadir el recurso de atribuir conductas terroristas a la comunidad vasca, como sucede con el comentario de Rafa "eso es muy típico de los radicales vascos", al referirse al hecho de quitar libertades. El hecho de que resulte una afirmación exagerada para ese contexto y que no esté fundada en ningún criterio, sino que provenga de clichés sin fundamentar, es lo que provoca cierto halo de humor a la situación, y esta exageración es asimismo plasmada en la versión subtitulada, lo que refuerza el efecto humorístico que encierra la escena.

En la película predomina el humor basado en los estereotipos sobre la comunidad vasca, pero también encontramos ejemplos en los que se hacen referencias explícitas a los estereotipos sobre andaluces en los que se les dibuja como vagos e incultos, como cuando Rafa, haciéndose pasar por vasco, arremete contra los andaluces haciendo uso de los típicos estereotipos:

(18) Decimoctavo ejemplo

\begin{tabular}{|c|c|}
\hline $\begin{array}{l}\text { VO. } \\
\text { Rafa: ¡A tomar por culo, ya hombre! No } \\
\text { solo tenemos que estar pagándoles las } \\
\text { siestas con nuestros impuestos, sino que } \\
\text { además vienen aquí a tirarse a nuestras } \\
\text { mujeres. }\end{array}$ & $\begin{array}{l}\text { VOS. } \\
\text { Rafa: To hell with him! Not only do our } \\
\text { taxes pay for their siestas but now they } \\
\text { come here and screw our women! }\end{array}$ \\
\hline
\end{tabular}

Esta descripción se mantiene sin ninguna modificación en la versión subtitulada, funcionando el humor siempre y cuando la audiencia meta sea conocedora de estos clichés. El problema que puede aparecer es que desde el exterior la imagen que se tiene sobre la comunidad española está basada en la idea de pasar el día durmiendo la siesta y ser unos seductores (estereotipo sobre los andaluces), sin distinguir entre las distintas comunidades que configuran España. 
Por el contrario, en el siguiente caso podemos ver como el humor basado en la idea preconcebida de la ignorancia de los andaluces funciona sin problemas en la versión subtitulada:

\section{(19) Decimonoveno ejemplo}

\begin{tabular}{|l|l|}
\hline $\begin{array}{l}\text { VO. } \\
\text { Joaquín: Que te han lavao la cabeza. Pero } \\
\text { no lo digo en sentido literario. Lo digo, } \\
\text { bueno en el literario también, porque te } \\
\text { han quitao la gomina y todo eso. }\end{array}$ & $\begin{array}{l}\text { Voaquín: They brainwashed you. I don't } \\
\text { mean in the "literary" sense... Well, that } \\
\text { too, because they took away your hair gel. }\end{array}$ \\
\hline
\end{tabular}

La ignorancia del andaluz se ve plasmada en la equivocación que tiene al utilizar la palabra "literario" en vez de "literal" para la expresión "en sentido literal". Esta paronimia funciona igual en inglés, lo que facilita la labor del traductor.

\subsection{Elementos lingüísticos}

En lo que respecta al humor basado en elementos lingüísticos, recordemos la cita de Newmark (1988: 107): "all jokes are translatable, but they do not always have the same impact". Sugiere que hay tres posibles métodos para traducir una palabra en un chiste con dos significados: 1) encontrar una palabra en la lengua meta que expresara los dos de la lengua origen, 2) sacrificar uno de los significados o distribuir los dos significados en varias palabras, y 3) usar un sinónimo con un significado doble similar. En la película nos encontramos con los siguientes ejemplos:

(20) Vigésimo ejemplo

\begin{tabular}{|l|l|}
\hline VO. & VOS. \\
Rafa: Camarero, & Rafa: Knock, knock! \\
Gente: ¿Qué? & Gente: Who's there? \\
Rafa: Una de trucha. & Rafa: Laura. \\
Gente: ¿Una de trucha? & Gente: Laura who? \\
Rafa: Trucha policía, poca diversión. & Rafa: "Laura Norder", cops at the door! \\
\hline
\end{tabular}

En este caso el efecto humorístico cuenta con un elemento lingüístico, que es el juego de palabras que se basa en el parecido fonético entre trucha y mucha y en el sentido resultante de la nueva expresión, donde se pasa de una cantidad elevada de policía a calificarla como homosexuales de manera despectiva por medio de la homonimia del término "trucha". En la versión subtitulada al inglés se mantiene la paronimia entre "Laura Norder" y law and order, y un final en el que se pretende ridiculizar a la policía. Este juego basado en una 
pregunta y una respuesta que consigue un efecto humorístico es conocido en ambas culturas. En la versión subtitulada, al preguntar por qué Laura está en la puerta se contesta Laura Norder, que suena igual que law and order, expresión utilizada por la policía al ir a irrumpir en algún lugar. La propuesta del traductor es doblemente acertada, ya que además de poder mantener el efecto humorístico, empleando el mismo tipo de elementos humorísticos, resulta adecuada al contexto en el que se produce: Rafa liderando una manifestación y haciendo frente a la policía.

Otro ejemplo es:

(21) Vigesimoprimero ejemplo

\begin{tabular}{|l|l|}
\hline VO. & VOS. \\
Currito: Los vascos no pueden vernos & Currito: The Basques can't stand the sight \\
a los andaluces ni en pintura. Eso se lo & of Andalusians. They're taught that in \\
enseñan allí en primero de sus escayolas. & baby Basque school. That and making \\
Eso y hacer cócteles Molotov. & Molotov cocktails.
\end{tabular}

En este, el referente cultural ikastola se convierte en un elemento lingüístico con función humorística. El referente, tomado del euskera y que significa colegio, es confundido por el andaluz con el término "escayola", lo que produce una paronimia. Este juego se pierde en la versión subtitulada, pero el humor se compensa al conservarse lo absurdo (humor NM) de asociar los colegios con que en ellos se enseñen prácticas terroristas como hacer cócteles Molotov. A pesar de que Fuentes (2001: 78), tras su estudio de la recepción del humor en el subtitulado, concluía que "los juegos de palabras quedan sin resolver y la transferencia literaria de las referencias culturales hace que resulten incomprensibles al receptor, que queda desorientado, extrañado o, en el mejor de los casos, no recibe efecto humorístico alguno", hay que reconocer la maestría del traductor en ciertos momentos, como el siguiente, en el que, a pesar de cierta pérdida, se procura conservar la misma concatenación humorística: 
(22) Vigesimosegundo ejemplo

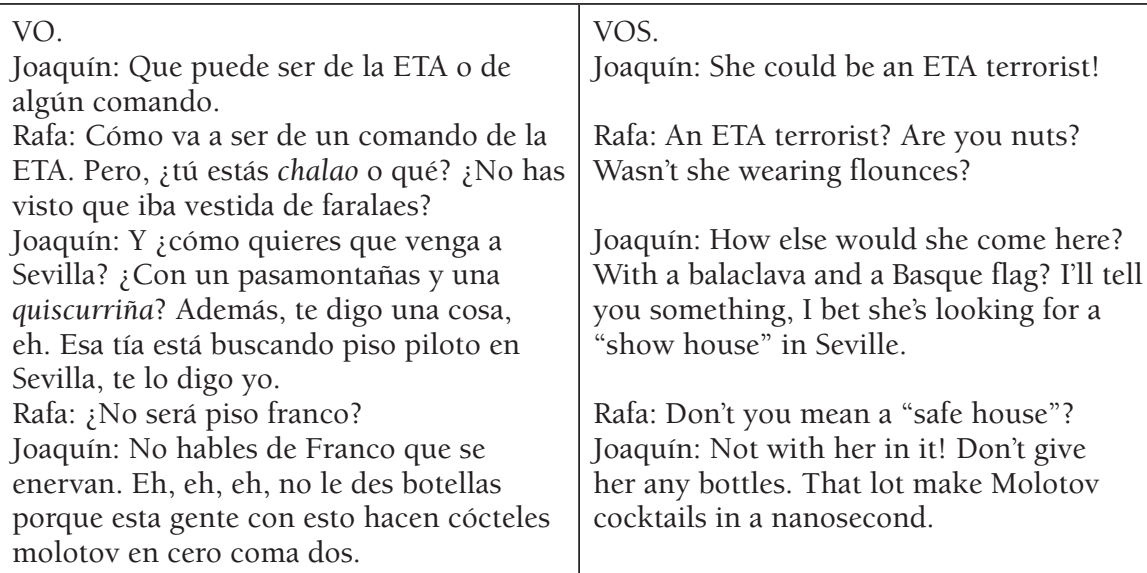

En este ejemplo se encuentran los referentes culturales de la ikurriña (la bandera vasca) y Franco. En el primer caso, el término vasco ikurriña es erróneamente pronunciado por el andaluz, lo que da lugar a una nueva palabra con cierta similitud fonética: "quiscurriña". Esta confusión desaparece, y por ende su toque humorístico, en la versión subtitulada, al traducirlo por medio de una explicitación del referente con el hipónimo "Basque flag". En el segundo caso, el humor es el resultado del equívoco que surge al utilizar la expresión "piso piloto" en lugar de "piso franco" y del juego que se establece entre el adjetivo "franco" y el apellido del dictador español. A pesar de lo complicado que pudiera resultar mantener esta cadena en la que cada eslabón acrecienta el humor, el traductor logra con éxito reproducir la sucesión. Para ello, recurre a la misma confusión en el uso de las expresiones show house y safe house que se produjera en la versión original, y al mismo sentido último del adjetivo que acompaña al sustantivo. Mientras en la versión original la alusión al político (CI) implica una provocación a la comunidad independentista, en la subtitulada se sacrifica el CI y su valor político en favor de la función humorística, que recae en la relación entre el adjetivo de casa "safe" y el hecho de que no es seguro tener a una vasca en el piso, al recaer en los clichés sobre los vascos y el terrorismo. 


\subsection{Elementos sobre la comunidad e instituciones}

Como se puede ver en el ejemplo anterior, la traducción de los referentes culturales (CI) puede resultar complicada, especialmente si la cultura meta no los comparte. Así sucede en:

(23) Vigesimotercer ejemplo

\begin{tabular}{|l|l|}
\hline VO. & VOS. \\
Compañero de celda: Oye, ¿y tú estás en & Compañero de celda: Are you in a terrorist \\
algún comando o...? & cell or...? \\
Rafa: Bueno, pues, pues puede ser. Vamos & Rafa: Well, I could be. I mean, yes, I am. \\
que sí. & Compañero de celda: Which one? \\
$\begin{array}{l}\text { Compañero de celda: ¿Cuál? } \\
\text { Rafa: El comando G. "Guipuzcoa" }\end{array}$ & Rafa: G cell. "Guipuzcoa". \\
\hline
\end{tabular}

En esta escena Rafa no sabe qué contestar al ser preguntado por su pertenencia a algún comando, y responde con el nombre de la serie de televisión de los años 80 Gatchaman, que llegó a España con el título Comando G. Su popularidad, conseguida a través del grupo Parchís, suscita el humor entre la audiencia origen, que encuentra este nombre nada apropiado para un comando terrorista. De ahí también la perplejidad del compañero de celda y que Rafa reaccione asociando la G con la inicial de la región vasca de Guipúzcoa. En la versión subtitulada el CI original se ha traducido, literalmente desapareciendo la alusión al anime en el texto meta. Sin embargo, la opción del traductor podría tratarse de un guiño a la película infantil G-Force (2009), lo que mantendría el humor basado en la candidez de Rafa por recurrir a un programa de su infancia a través de una referencia intertextual.

La dificultad que implica la traducción de CI queda igualmente demostrada en la escena que da título a la película en su versión original: 
(24) Vigesimocuarto ejemplo

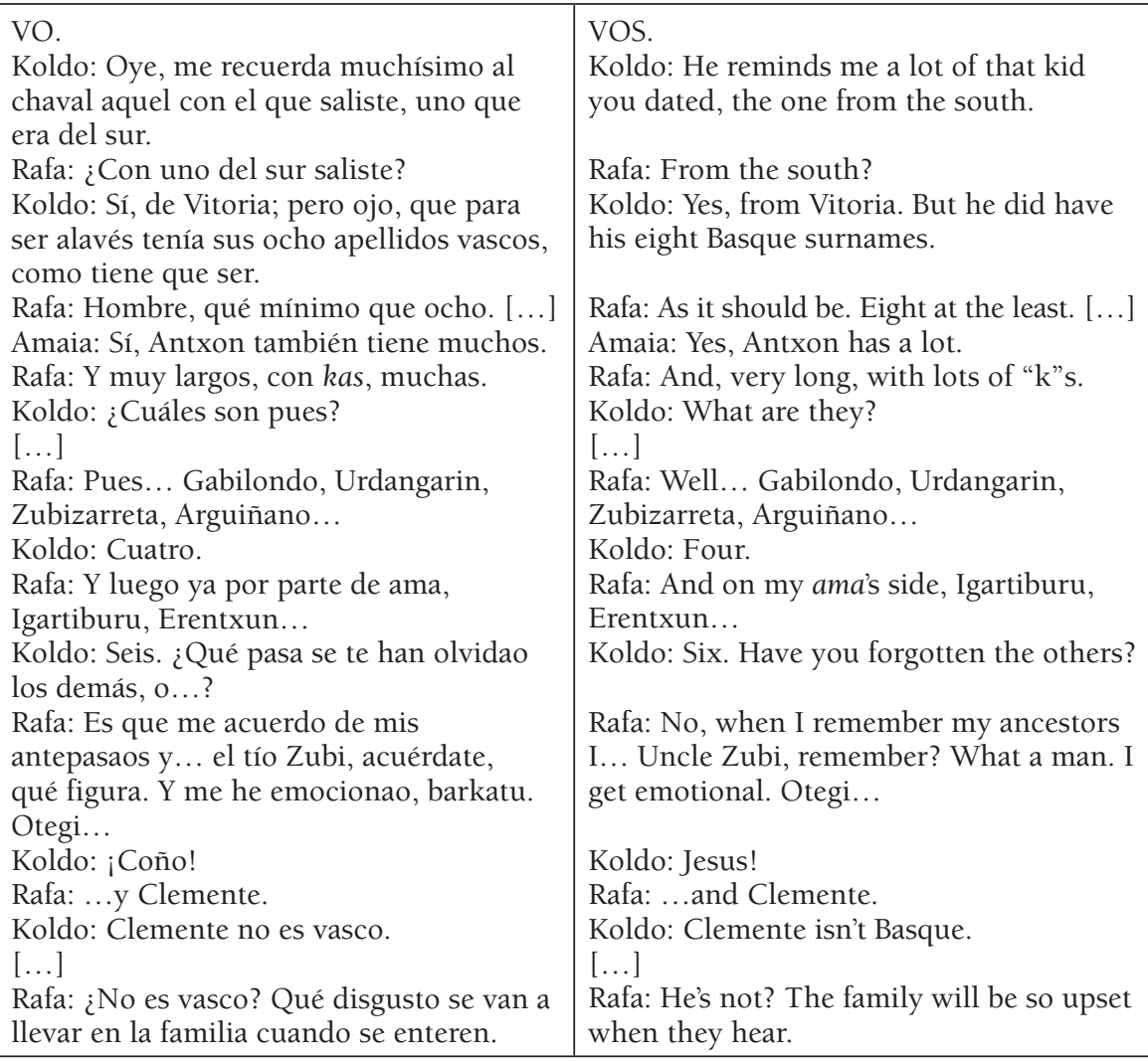

El primer problema que surge es que la acción y el humor que en ella se desencadena están basados en un concepto de la comunidad (SHC). La práctica de llevar el apellido paterno y materno está arraigada en la sociedad española desde el siglo XIV (Herzog 2007: 10), y tener ocho apellidos vascos se traduciría en que nos encontramos ante una persona que al menos tiene dos generaciones de procedencia puramente vasca. Este concepto español de reconocer y tener presentes los apellidos de ambas ramas de la familia puede resultar desconocido para un extranjero. Si a esto se suma que los apellidos que se proporcionan en la película corresponden a su vez a personajes de la cultura origen $(\mathrm{CI})$ con vinculación a la comunidad vasca, se complica más aún su traducción. El humor radica en aunar distintas personalidades que van desde periodistas, deportistas o cocineros hasta miembros de la familia real y terroristas. Así también si la audiencia meta no reconoce que el apellido Otegui 
se trata del de un terrorista, la exclamación de Koldo carecerá de sentido. El humor no se conseguirá tampoco si la audiencia meta no reconoce la referencia visual en la foto del Athletic al entrenador de fútbol Víctor Clemente, todo un emblema del equipo bilbaíno, y cuyo apellido utiliza Rafa al no recordar más referentes populares entre la comunidad vasca.

En esta misma línea de CI conflictivos para la audiencia meta se encuentra:

(25) Vigesimoquinto ejemplo

\begin{tabular}{|l|l|}
\hline VO. & VOS. \\
Rafa: Koldo, te presento a Anne, mi ama. & Rafa: Koldo, this is Anne, my ama. \\
{$[\ldots]$} & {$[\ldots]$} \\
Koldo: Anne... ilgartiburu? ¡Ay va, la & Koldo: Anne... Igartiburu? Hell, there's a \\
hostia, casualidad también! & coincidence! Yes, like the girl on TV. \\
{$[\ldots]$} & {$[\ldots]$} \\
Koldo: Bai. Agur. & Koldo: Bai. Agur. \\
Merche: Hasta mañana, corazones. & Merche: See you tomorrow, my dears. \\
\hline
\end{tabular}

Aquí, el nombre que elige Merche para pasar por vasca junto con el apellido que había elegido Rafa en su faceta vasca corresponde con el de una presentadora de un programa del corazón. El humor surge al imitar Merche la forma de hablar y la fórmula que emplea esta presentadora para despedirse (P). La audiencia meta, a menos que sea conocedora del programa televisivo, únicamente advertirá el CI gracias al hiperónimo "the girl on TV", pero no establecerá ninguna relación entre la fórmula que utiliza para despedirse Merche y la imitación de la presentadora, perdiendo parte de la carga humorística (P).

Por el contrario, si el referente es compartido, la labor del traductor se facilita y el humor se traslada fluidamente, como en la escena en la que Rafa se vale de una frase épica de una película infantil para apelar a la lucha callejera por la independencia:

\section{(26) Vigesimosexto ejemplo}

\begin{tabular}{|l|l|}
\hline VO. & VOS. \\
Rafa: Hay que esconderse y esperar & Rafa: Hide and wait for orders from above. \\
$\begin{array}{l}\text { ordenes de arriba. [...] ¡Hasta la } \\
\text { independencia y más allá! }\end{array}$ & {$[\ldots]$ To independence and beyond! } \\
Chico: Oye, ipero eso no es de Toy Story? & Chico: Isn't that from "Toy Story"? \\
\hline
\end{tabular}

\subsection{Elementos visuales}

La película, que utiliza el humor cultural como desencadenante de la trama desde sus primeras secuencias, recurre al mismo para cerrar la historia de los 
personajes. En las últimas escenas se ratifica la aseveración de Martínez Sierra (2009: 147) sobre el hecho de que, aunque el componente visual en muchas ocasiones puede contribuir a entender mejor el texto meta y a facilitar el humor, cuando a este se suma el componente cultural el traductor se encuentra con restricciones que difícilmente se pueden superar. Este es el caso (vigesimoséptimo ejemplo) de la escena en la que Koldo, tras pasar la noche con Merche, descubre en el dormitorio numerosos objetos muy representativos de España y de sus instituciones, como es una figurita de un guardia civil sobre la mesilla, una bandera de España junto a un cuadro del rey, un plato con la bandera de España o un almohadón en el que se lee España y se ve a un andaluz y a una sevillana bailando. Las referencias a España siguen en el resto de la casa. Así, nada más salir del dormitorio Koldo se encuentra con un cuadro donde se lee "Forever Caceres", una placa de la guardia civil y, finalmente, una foto de Merche con su marido vestido de guardia civil, junto a un cuadro con la bandera de España y el toro de Osborne. La situación humorística nace ante la cara perpleja de Koldo (V) al descubrir todos los elementos representativos de la comunidad e instituciones (CI) y que tienen el valor añadido de relacionarse con valores y creencias de la comunidad (SHC) asociados a la exaltación de España como nación y que chocan con su concepción independentista. Sin embargo, el espectador que desconozca el valor atribuido a los guardias civiles como defensores de la unidad de España puede no comprender cómo Koldo se sorprende al descubrir que Merche estuviera casada con un guardia civil y que ahora esté enamorada de un independentista como él.

\section{Conclusión}

Como se ha podido observar tras el análisis, a las restricciones propias del subtitulado se ha sumado la complejidad que entraña la traducción del humor y, en particular, el alto contenido cultural que converge en Ocho apellidos vascos. El papel tan importante que juega el humor en la película, junto con la elevada carga cultural complica, la ardua tarea del traductor y cuestiona en ciertos momentos nuestra hipótesis de partida sobre la traducibilidad del humor. A pesar de esto, de la investigación se desprende que, en términos de una evaluación global, se consigue reflejar el humor en el subtitulado, dejando patente la profesionalidad y creatividad del traductor, al ser mínima la diferencia de elementos de humor encontrada entre la versión original (37 elementos) y la subtitulada (34 elementos).

En términos de una evaluación parcial centrada en los resultados de la traducción al subtitulado de los elementos de humor por separado, se advierte un cambio de tipos de elementos humorísticos en la versión subtitulada (Gráfica 1). 

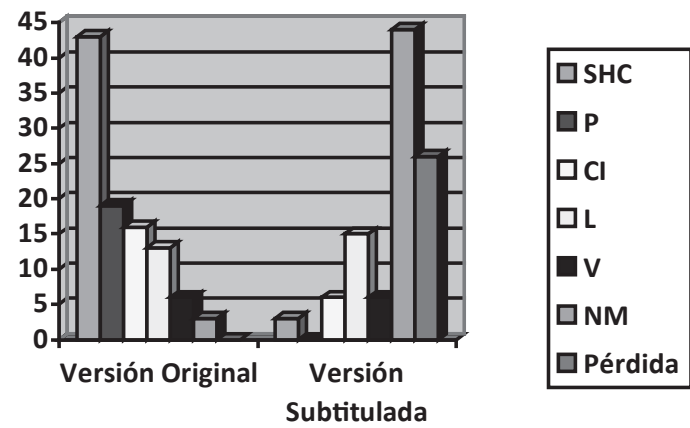

Gráfica 1 - Porcentajes de tipos de elementos de humor en la versión original y en la subtitulada.

En la versión original destaca el número de casos en los que el humor reside en elementos de SHC, 16 en los 27 ejemplos analizados (ejemplos: 6-19, 24 y 27), seguidos por los elementos P con 7 casos (ejemplos: 2-7 y 25), los CI con 6 casos (ejemplos: 21-26), los L con 5 casos (ejemplos: 6-7 y 20-22), los V con 2 casos (ejemplos: 16 y 27) y los NM con 1 caso (ejemplo: 1). La preferencia por el uso de elementos SHC como recurso humorístico en la versión original es notable y, tal y como apuntara Fuentes (2001: 78), se advierte una pérdida del efecto humorístico por un posible desconocimiento de los valores atribuidos a la comunidad y en los que se sustentan los estereotipos. De ahí la importancia de tener en cuenta la audiencia cuando se trata de humor cultural, al ser el que más desafíos presenta (Eleni 2004). Asimismo, el humor en la película proviene de los estereotipos reflejados y del choque entre ellos. Estos estereotipos no se limitan a la forma de vestir o peinar, sino que van más allá, atendiendo a ideologías que se ven plasmadas muchas veces en el uso de la lengua. La tesis de Deacon (1997: 419), apoyada por Vandaele (2010), sobre el papel social del humor como una forma de mantener la cohesión e identidad del grupo se ve constatada tras el análisis realizado. Se comprueba que los integrantes de las mismas comunidades comparten un mismo sentido del humor y optan, frecuentemente, por recurrir a los mismos tipos de elementos humorísticos. Ese choque entre culturas y tradiciones que mantiene la tensión a lo largo de la película culmina con la reconciliación de culturas que simboliza la unión de los protagonistas. Asimismo, si prestamos atención a los elementos de humor en la versión subtitulada, encontramos que asciende notablemente el número de elementos NM en detrimento de los SHC; esto se debe a que en muchos de ellos la imposibilidad de traducir parte del discurso, como sucede en los ejemplos 2, 4, 5, 6 y 7 desencadena una situación absurda que lleva al humor. 
Junto a los elementos humorísticos culturales SHC, los elementos P, en particular los referidos al acento y formas de hablar, son numerosos y desempeñan una función humorística clave en la versión original que es difícil trasladar en el subtitulado. Aquí se produce una pérdida de carga humorística que se ve parcialmente subsanada cuando estos elementos se combinan con otros que persiguen el mismo fin, como pueden ser los L en los ejemplos 6 y 7. A pesar de que el humor basado en elementos L se consigue trasladar por medio de equivalentes a la lengua meta (ejemplos 20 y 22), este trasvase se ve afectado en los momentos en los que los elementos $L$ van vinculados a aspectos culturales, tal y como sucede en el ejemplo 21. De este modo se corroboran las palabras de Vandaele (2010: 149), quien apunta a los aspectos culturales y lingüísticos como desencadenantes de esta imposibilidad.

En lo que respecta a los elementos CI, se percibe que el trasvase del humor es viable en aquellos casos en los que el tipo de referente encuentra un equivalente en la cultura meta (ejemplo 23) o es común a las dos culturas (ejemplo 26). Si, por el contrario, el humor reside únicamente en este elemento y el referente no puede modificarse (ejemplo 24), se produce una pérdida en el humor al resultar oscura a la audiencia meta que no consigue comprender su significado final en la escena.

En el caso de los elementos $\mathrm{V}$ únicamente pueden resultar confusos en las escenas donde el valor simbólico de estos elementos está vinculado a aspectos o figuras muy específicas de la cultura origen que resulten desconocidos por la audiencia meta. Sin embargo, si se trata de una combinación de estos que da lugar a un retrato de una situación cómica, el desconocimiento de alguno de ellos se ve compensado por el resto y su trasvase es factible, como en el ejemplo 27.

Así podemos concluir que, al contrario de lo que pudiera parecer a priori tanto por el marcado aspecto cultural de la película como por un análisis basado en ejemplos aislados, el humor es traducible, si bien esa traducibilidad es gracias a un cambio en el tipo de humor empleado en aquellos casos donde la conservación del mismo elemento humorístico del original resulta inviable.

Por último, nos gustaría señalar que, a pesar de que el humor ha sido objeto de estudio en numerosas ocasiones, no muchos artículos se han centrado en su traducibilidad en películas que tienen como hilo narrativo las diferencias culturales y cuyo humor proviene precisamente de estas, y menos en la modalidad de la subtitulación. Por ello, este artículo ha procurado contribuir al estudio de la traducción del humor en este tipo de películas y, en concreto, en el subtitulado, por entender que estas películas se proyectan subtituladas en otros países con distinta lengua en los que se busca una mayor difusión 
tanto del producto audiovisual como de la cultura origen. Sin embargo, somos conscientes de que todavía queda mucho camino por recorrer y desde aquí se desea animar a complementar este estudio con investigaciones sobre la recepción del humor que resultarían esenciales para poder afirmar que el humor es traducible en este tipo de películas y en las que se evaluarían los efectos sobre el espectador al perderse alguna referencia concreta.

\section{Bibliografía}

ATTARDO, Salvatore \& Victor Raskin. (1991) "Script theory revis(it)ed: Joke similarity and joke representation model." Humor-international journal of humor research 4:3-4, pp. 293-348.

ChIARO, Delia. (2000) "Servizio completo. On the (un)translatability of puns on screen." En: Bollettieri Bosinelli, Rosa Maria; Christine Heiss; Marcello Soffritti \& Silvia Bernardini (eds.) 2000. La traduzione multimediale. Quale traduzione per quale testo? Bolonia: CLUEB, pp. 27-42.

CHIARO, Delia. (2005) "Verbally expressed humor and translation: An overview of a neglected field." Humor, international journal of humor resaerch. Special issue in humor and translation 18:2, pp. 135-145.

CHIARO, Delia. (2010) "Translation and humour, humour and translation." En: Chiaro, Delia (ed.) 2010. Translation, humour and literature. Translation and humour. Londres: Continuum, pp. 1-32.

DEACON, Terrence. (1997) The symbolic species: The co-evolution of language and the brain. Nueva York: Norton.

Del CoRral, Irene. (1988) "Humor: When do we lose it?" Translation Review 27, pp. 25-27.

Delabastita, Dirk. (1996) "Introduction." En: Delabastita, Dirk (ed.) 1996. The Translator. Studies in intercultural communication 2:2. Mánchester: St Jerome, pp. 127-139.

ELENI, Antonopoulou. (2004) "Humor theory and translation research: proper names in humor discourse." Humor international journal of humor research 17:3, pp. 219- 255.

FUENTES, Adrián. (2000) "Estudio empírico sobre la recepción del humor audiovisual." En: Lorenzo, Lourdes \& Ana María Pereira (eds.) 2000. Traducción subordinada (II). El subtitulado. Vigo: Servicio de Publicaciones de la Universidad de Vigo, pp. 69-84.

FUENTES, Adrián. (2001) La recepción del humor audiovisual traducido: estudio comparativo de fragmentos de las versiones doblada y subtitulada al español de la película Duck Soup, de los hermanos Marx. Granada: Universidad de Granada. Tesis doctoral inédita. 
GotTlieb, Henrik. (1992) "Subtitling-a new university discipline." En: Teaching translation and interpreting: training, talent and experience. Ponencias de The first language international conference, Elsinore, Dinamarca 31 Mayo-2 Junio 1991. Ámsterdam \& Filadelfia: John Benjamins Publishing Company, pp. 161-170.

Gottlieb, Henrik. (1994) "Subtitling: diagonal translation." Perspectives, Studies in Translatology 2, pp. 101-121.

Herzog, Tamar. (2007) "Nombres y apellidos: ¿cómo se llamaban las personas en Castilla e Hispanoamérica durante la época moderna?" Jahrbuch für Geschichte Lateinamerikas 44, pp. 1-35.

MARTÍNEZ SiERRA, Juan José. (2004) Estudio descriptivo y discursivo de la traducción del humor en textos audiovisuales. El caso de Los Simpson. Castellón: Universitat Jaume I. Tesis doctoral inédita.

MARTínez Sierra, Juan José. (2009) "El papel del elemento visual en la traducción del humor en textos audiovisuales: ¿un problema o una ayuda?" TRANS: Revista de traductología 13, pp. 139-148.

NASH, Walter. (1985) The language of humour (English language series). Nueva York: Longman Publishing Group.

Newmark, Peter. (1988) A textbook of translation. Nueva York: Prentice Hall.

SANTANA LóPEZ, Belén. (2005) "La traducción del humor no es cosa de risa: un nuevo estado de la cuestión.” En: Romana García, María Luisa (coord.) 2005. Actas del II Congreso Internacional AIETI 2005. Formación, investigación y profesión. Madrid, 9-11 de febrero 2005, pp. 834-851.

SANTOYO, Julio César. (1994) "Traducción de cultura, traducción de civilización." En: Hurtado Albir, Amparo (ed.) 1994. Estudis sobre la traducció. Castellón: Universitat Jaume I, pp. 141-152.

VANDAELE, Jeroen. (2002) "Introduction: (Re-)Constructing humour: Meanings and means." The Translator 8:2, pp. 149-172.

VANDAELE, Jeroen. (2010) "Humor in translation." Handbook of translation studies 1 , pp. 147-152.

ZabalbeasCOA, Patrick. (1996) "Translating jokes for dubbed television situation comedies." En: Delabastita, Dirk (ed.) 1996. The Translator: Studies in intercultural communication. Mánchester: St. Jerome, pp. 235-257.

ZabAlBEASCOA, Patrick. (1997) "Dubbing and the nonverbal dimension of translation." En: Poyatos, Fernando (ed.) 1997. Nonverbal Communication and Translation. New Perspectives and Challenges in Literature, Interpretation and the Media. Ámsterdam \& Filadelfia: John Benjamins Publishing Company, pp. 327-342. 


\section{BIONOTE / NOTA BIOGRÁFICA}

Pilar GonZÁlez-Vera se doctoró en Filología Inglesa por la Universidad de Zaragoza. Es profesora de traducción audiovisual e inglés técnico (ingeniería y arquitectura) en la Universidad de Zaragoza. Pertenece al grupo de investigación Swift y ha participado en programas de innovación docente como "Icap-Intralingual captioning for writing and vocabulary enhancement within an integrated skills framework" $y$ "Subtitle for the deaf and hard of hearing to improve listening and writing skills in foreign language education".

Sus intereses docentes e investigadores incluyen la traducción audiovisual y la accesibilidad; la traducción del humor y aspectos culturales; y el uso de las nuevas tecnologías y la traducción audiovisual en la enseñanza de segundas lenguas. Ha publicado en revistas como Ikala, JoSTrans, Language Value, Miscelanea o RILA. Es miembro del comité editorial Journal for English Linguistics y científico de la revista Verbeia.

PILAR GONZÁlEZ-VERA completed her PhD in English Philology at the University of Zaragoza. She is a lecturer of audiovisual translation and technical English at the University of Zaragoza. She is a researcher in the group Swift and has participated in innovative teaching networks like "Icap-Intralingual captioning for writing and vocabulary enhancement within an integrated skills framework" and "Subtitle for the deaf and hard of hearing to improve listening and writing skills in foreign language education". Her research interests include audiovisual translation and accessibility; the translation of humour and cultural references; and the use of new technologies and audiovisual translation in SLA. She has published in various journals, including Ikala, JoSTrans, Language Value, Miscelanea, and RILA. She is also in the editorial board of the Journal for English Linguistics and in the scientific board of Verbeia. 
